\title{
De pequenito se trata o dentito - o papel do Médico de Família
}

Darcília Eusébio*

\section{RESUMO}

Objectivo: Rever as principais recomendações baseadas na evidência para a prevenção da CPI em Cuidados de Saúde Primários. Fontes de Dados: Medline, Guidelines Finder, National Clearinghouse, The Cochrane Library, CMA, DARE, TRIP, Bandolier.

Métodos de Revisão: Pesquisa de guidelines, meta-análises, artigos de revisão e estudos aleatorizados e controlados, publicados entre Janeiro de 2005 e Novembro de 2008, em inglês e português, com abstract disponível, utilizando as palavras-chave (termos MESH) Dental caries, Infant, Primary Health Care. Para avaliar o nível de evidência, foi utilizada a escala SORT (Strength Of Recommendation Taxonomy) da American Family Physician.

Resultados: Dos 54 artigos encontrados, foram seleccionados 17, dos quais 12 Normas de Orientação Clínica, uma revisão sistemática e 4 estudos aleatorizados e controlados. As actuais recomendações incidem na prevenção da transmissão das bactérias cariogénicas, na implementação de medidas de higiene oral o mais precocemente possível, na prestação de cuidados antecipatórios de evicção de comportamentos cariogénicos, na suplementação adequada e individualizada de flúor e na referenciação preventiva ou justificada (diagnóstico precoce/risco acrescido).

Conclusões: O Médico de Família/Pediatra é frequentemente o primeiro e único profissional de saúde a observar e acompanhar o desenvolvimento das crianças, encontrando-se, por isso, numa posição única para actuar activamente na prevenção da CPI pela prestação de cuidados antecipatórios, avaliação do risco, diagnóstico precoce e orientação adequada.

Palavras-chave: Cárie Dentária; Criança; Cuidados de Saúde Primários.

\section{INTRODUÇÃO}

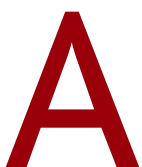

A cárie dentária é a doença crónica mais prevalente da infância. Nas crianças em idade pré-escolar denomina-se Cárie Precoce da Infância (CPI) e pode ser tão precoce que pode ser diagnosticada logo após a erupção dos primeiros dentes (Figura 1). ${ }^{1}$

ACPI influencia desfavoravelmente a saúde global da criança, diminui a função mastigatória, altera o desenvolvimento e a estética facial, provoca perturbações fonéticas, condiciona a correcta erupção dos dentes permanentes, causa dor e origina complicações infecciosas com repercussão local e sistémica. É um processo cumulativo, progressivo e predictivo de cáries na dentição permanente. ${ }^{1-3}$

Em Portugal, os estudos de prevalência da cárie den-

* Médica de Família

Centro de Saúde Bonfim/Batalha - Extensão Barão de Nova Sintra tária são escassos. A Sociedade Portuguesa de Estomatologia e Medicina Dentária, com o apoio da Colgate, realiza anualmente, em Outubro, um rastreio popula-

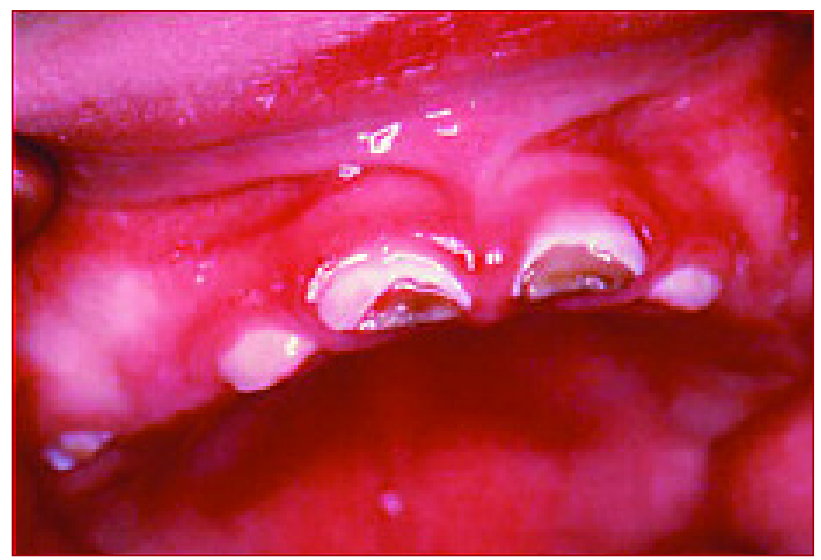

Figura 1. Cárie dentária severa nos primeiros dentes de um bebé (http://www.aafp.org/afp/20041201/2113_f2.jpg)

Disponível em: http://www.aafp.org/afp/20041201/2113.pdf 
cional gratuito. O rastreio de Outubro de 2007, que incluiu 2.255 crianças com idades inferiores a 8 anos e com média de idades de 5,1 anos, registou que 50,1\% das crianças no grupo etário dos 6 anos apresentavam dentes cariados. ${ }^{4}$

Uma vez que se trata de uma amostra de âmbito voluntário, os resultados, ainda que sujeitos ao cálculo de taxas padronizadas de modo a ajustar às estimativas para a população portuguesa, poderão não ser representativos da mesma.

O Programa Nacional de Promoção da Saúde Oral em vigor no nosso País refere que a cárie dentária na população infantil e juvenil portuguesa apresenta um índice de gravidade moderada, sendo a percentagem de crianças livres de cárie dentária aos seis anos de idade de apenas $33 \% .^{5}$

\section{Fisiopatologia da Cárie Dentária}

A cárie dentária é uma doença de etiologia bacteriana e carácter multifactorial. O processo cariogénico implica a conjugação simultânea de três factores: bactérias, açúcares e dentes. ${ }^{1-3,6,7}$

Após cada refeição, as bactérias presentes na cavidade oral, particularmente a espécie

Streptococcus mutans e algumas espécies de Lactobacillus (para simplificar a referência ao longo do trabalho, estas bactérias são denominadas no seu conjunto como «bactérias cariogénicas») fermentam os hidratos de carbono com produção de ácidos orgânicos que acidificam o meio e favorecem à dissolução/desmineralização do esmalte. A saliva, como solução tampão, repõe o pH da cavidade oral em aproximadamente quarenta minutos, seguindo-se uma fase de remineralização.

Assim, a ingestão frequente de alimentos ou a presença prolongada de restos alimentares na cavidade oral, na presença daquelas bactérias, desequilibra este processo, no sentido da acidificação persistente do meio com consequente destruição progressiva e centrípeta dos tecidos mineralizados dos dentes.

A cárie dentária é, portanto, uma doença infecciosa e transmissível, que pode ser prevenida, se a intervenção primária actuar simultaneamente nos seus três factores fisiopatológicos: bactérias, açúcares e dentes.

\section{Pergunta de Revisão}

Qual é o papel dos Cuidados de Saúde Primários, no- meadamente do Médico de Família/Pediatra, na prevenção da CPI?

\section{Objectivo}

O objectivo deste trabalho foi rever as principais recomendações baseadas na evidência para a prevenção da CPI em Cuidados de Saúde Primários e os respectivos graus de força aplicando a taxonomia SORT.

\section{MÉTODOS}

Foi realizada uma pesquisa de artigos publicados nas bases de dados Medline, Guidelines Finder, National Clearinghouse, The Cochrane Library, CMA, DARE, TRIP e Bandolier, entre Janeiro de 2005 e Novembro de 2008, em inglês e português, com abstract disponível, utilizando as palavras-chave (termos MeSH) Dental caries, Infant, Primary Health Care.

Foram seleccionados artigos de revisão, normas de orientação clínica (guidelines), estudos aleatorizados e controlados e meta-análises. Obtiveram-se 54 artigos. Destes, foram eliminados: 7 artigos que se encontravam repetidos, 11 por abordarem procedimentos realizados por Medicina Dentária, 4 por abordarem medidas de Saúde Pública, 11 eliminados pelo título e/ou abstract (referentes a populações com necessidades de cuidados de saúde especiais). Foram adquiridos 21 artigos. Após leitura destes, 4 foram eliminados por se afastarem dos objectivos da revisão.

Foram incluídos nesta revisão 17 artigos, dos quais 12 Normas de Orientação Clínica, 1 revisão sistemática e 4 estudos aleatorizados e controlados.

As recomendações resultantes desta pesquisa foram posteriormente confrontadas com as recomendações do Programa Nacional de Promoção da Saúde Oral em vigor - Despacho Ministerial n. ${ }^{\circ}$ 153/2005 (2a Série).

\section{RESULTADOS}

As estratégias de prevenção da CPI devem incidir nos seus três factores fisiopatológicos primários (A) nomeadamente na redução da carga bacteriana, na redução da disponibilidade de açúcares refinados e no aumento da resistência dos dentes. ${ }^{1,3,6}$

Existem escalas para avaliação individual do risco de cárie (B), que incluem múltiplas variáveis consideradas factores de risco acrescido para o desenvolvimento de CPI. ${ }^{1-3,6,7}$ 


\section{A. Factores fisiopatologicos primários Reduzir a carga bacteriana}

Transmissão vertical

A colonização pelas bactérias cariogénicas ocorre aquando da erupção da dentição primária, entre os $6 \mathrm{e}$ os 30 meses de idade. A transmissão vertical da mãe (ou outro principal cuidador) para a criança está bem documentada. ${ }^{1,8}$ Portanto, medidas que modifiquem a flora oral materna na idade de risco de colonização podem reduzir significativamente o risco de cárie na criança.

Os cuidados antecipatórios a promover junto da mãe, antes e durante o processo de colonização, devem incidir nas medidas de higiene oral materna e na sensibilização para não partilhar com a criança utensílios e alimentos levados à boca (colheres, copos, «limpar a chupeta»). É ainda aconselhado que a mãe mastigue pastilhas de xilitol, especialmente após as refeições. O xilitol é um açúcar que não é fermentado pelas bactérias cariogénicas e, ao promover a secreção salivar e a restauração do $\mathrm{pH}$ da cavidade oral, parece diminuir o reservatório de bactérias na cavidade oral da mãe, diminuindo o risco de cáries na mãe e na criança. ${ }^{6}$

\section{Higiene oral}

A remoção da placa bacteriana pelos cuidados de higiene oral é uma medida preventiva eficaz e deve ser iniciada o mais precocemente possível, aquando da erupção dos primeiros dentes.

\section{Flúor}

O objectivo primário da suplementação com flúor é prevenir a cárie dentária ou atrasar a progressão das lesões já existentes. A fluorose dentária é o efeito adverso mais frequente, como consequência de uma ingestão excessiva de flúor e que se caracteriza por uma hipomineralização do esmalte. Este efeito adverso é maior com a suplementação sistémica mas também existe com a suplementação tópica, actualmente a mais defendida, por se considerar que os benefícios do flúor resultam principalmente da inibição da desmineralização e aumento da remineralização nas superfícies do esmalte, e pela inibição local da actividade bacteriana. O benefício da suplementação sistémica é mínimo quando é usado simultaneamente um flúor tópico, aumentando significativamente o risco de fluorose. ${ }^{1,6}$

A maior parte dos casos de fluorose diagnosticados é, contudo, de tipo leve ou muito leve, caracterizandose por dentes com um aspecto mosqueado ou com estrias brancas, e apenas de compromisso estético. ${ }^{9}$

O período crítico para o desenvolvimento de fluorose dentária nos dentes incisivos superiores é entre os 22-25 meses. ${ }^{1}$

Neste contexto, preconiza-se que os suplementos sistémicos de flúor sejam prescritos após avaliação individual do risco de cárie e cálculo do aporte total diário de flúor. Neste cálculo, devem ser necessariamente considerados o teor de flúor da água de consumo e os suplementos tópicos de flúor. ${ }^{1,6,8,10,11}$

As Associações Americanas de Médicos de Família (American Academy of Family Physicians), de Pediatria (American Academy of Pediatrics), de Medicina Dentária (American Dental Association) e de Pediatria Dentária (American Academy of Pediatric Dentistry) defendem que os suplementos sistémicos de flúor devem ser prescritos com o objectivo de compensar o défice de flúor da água de consumo (Quadro I). ${ }^{6,10}$

\section{Medidas preventivas de Higiene ORAL}

- A escovagem dos dentes com dentífrico fluoretado é um método globalmente aceite para prevenção da CPI e deve iniciar-se logo aquando a erupção dos primeiros dentes..$^{1-3,6,7}$

- Os dentes devem ser escovados todos os dias, duas vezes ao dia, uma delas necessariamente à noite antes de dormir. Durante o sono, o fluxo salivar diminui, permitindo uma maior acção tópica do flúor (ou das bactérias se os dentes não forem escovados). ${ }^{1,7}$

- O dentífrico usado deve ter uma concentração de flúor de $1.000 \mathrm{ppm} \pm 10 \%$. A quantidade de dentífrico a usar não deve ser maior do que um «borrão» nas crianças com idade inferior a 2 anos ou «uma ervilha» nas crianças entre os 2 e os 5 anos (Figura 2). Usar uma quantidade reduzida de um dentífrico mais concentrado parece ser mais eficaz e com menor risco de fluorose do que usar uma quantidade maior de um dentífrico menos concentrado.

- A escova deve ser adequada ao tamanho da boca da criança, com cerdas de dureza média ou macia. A escova pode ser manual ou eléctrica; ambas são igualmente eficazes. ${ }^{1}$ Pode ainda ser usada uma dedeira ou uma gaze própria. ${ }^{12}$

- As crianças devem ser encorajadas a cuspir o exces- 


\begin{tabular}{|c|c|c|c|}
\hline \multicolumn{4}{|c|}{$\begin{array}{l}\text { QUADRO I. Suplementação sistémica de Flúor ajustada } \\
\text { ao teor de Flúor da água de consumo (Adaptado de } \\
\text { HealthPartners Dental Group and Clinics caries } \\
\text { guideline. Minneapolis (MN): HealthPartners Dental } \\
\text { Group; 2008) }\end{array}$} \\
\hline \multirow[b]{3}{*}{ Idade } & \multicolumn{3}{|c|}{ Suplementos de Flúor/dia (mg) } \\
\hline & \multicolumn{3}{|c|}{$\begin{array}{l}\text { Concentração Flúor na } \\
\text { água de consumo }\end{array}$} \\
\hline & $<0,3 p p m$ & 0,3-0,6ppm & $>0,6 \mathrm{ppm}$ \\
\hline $0-6$ meses & 0 & 0 & 0 \\
\hline 6 meses -3 anos & 0,25 & 0 & 0 \\
\hline $3-6$ anos & 0,5 & 0,25 & 0 \\
\hline
\end{tabular}

Abreviaturas: mg - miligramas; ppm - partículas por milhão

so de dentífrico e a não enxaguar com água posteriormente de forma a permitir uma maior acção tópica do flúor. ${ }^{1}$

- A escovagem dos dentes deve ser realizada pelos pais ou supervisionada por eles de forma a controlar a quantidade de dentífrico aplicado e potencialmente ingerido. $\mathrm{O}$ uso abusivo de um dentífrico fluoretado, com mais de duas escovagens por dia e/ou com quantidades maiores de dentífrico, aumenta o risco

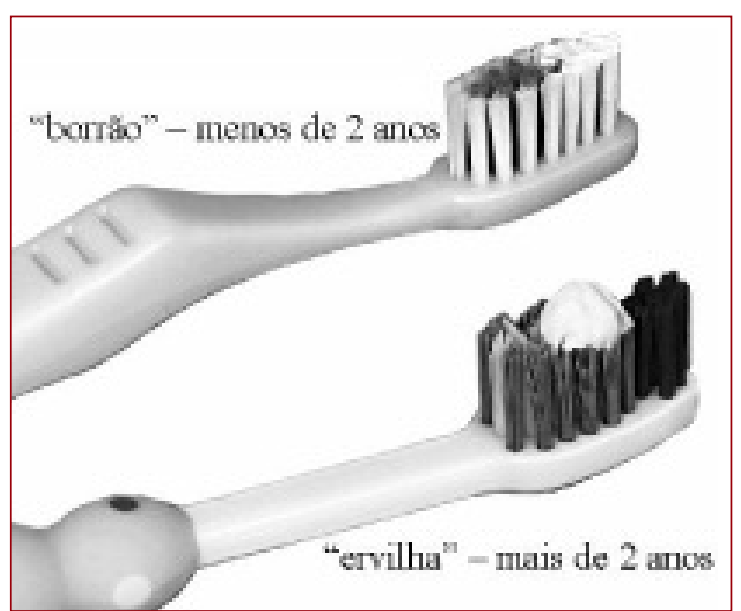

Figura 2. A quantidade de dentífrico a usar deve ser semelhante a um «borrão» nas crianças com idade inferior a 2 anos ou «uma ervilha» nas crianças entre os 2 e os 5 anos. (Adaptado de Scottish Intercollegiate Guidelines Network. Prevention and management of dental decay in the pre-school child. A national clinical guideline. Edinburgh: Scottish Intercollegiate Guidelines Network (SIGN); 2005). de ingestão e, consequentemente, de fluorose dentária. ${ }^{1}$

\section{Reduzir a disponibilidade de açúcares refinados}

Os açúcares simples (Figura 3) são os mais implicados no processo cariogénico por serem facilmente metabolizados pelas bactérias cariogénicas.

A ingestão frequente de açúcares simples proporciona um substrato constante para a actividade bacteriana que facilmente os fermentam com produção de ácidos orgânicos. A acidificação persistente do meio favorece a dissolução/desmineralização do esmalte, com aumento do risco de cáries. ${ }^{1,6,8,13}$

As crianças ingerem alimentos com maior frequência sendo, por isso, o grupo etário com maior risco de desenvolver cárie dentária.

Neste contexto, vários estudos têm procurado definir qual a «frequência segura» para a ingestão de alimentos, particularmente, açúcares. A evidência científica actual indica que a ingestão de açúcares quatro vezes por dia, incluindo os açúcares ingeridos às refeições, é compatível com uma boa saúde dentária. ${ }^{13}$

\section{Medidas preventivas de Educação Alimentar}

- As crianças não devem ser deitadas com o biberão por favorecer um uso mais prolongado do mesmo. Ainda que seja esta prática a responsável pela denominação anterior de «Nursing Caries» ou «Baby Bottle Tooth Decay", a associação entre CPI e o uso de biberão é fraca. ${ }^{1}$

- A duração do uso do biberão por si só não parece au-

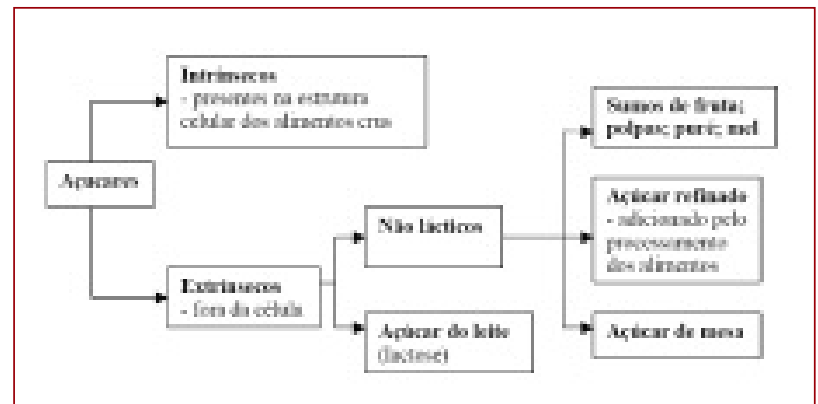

Figura 3. Classificação dos açucares da dieta. (Adaptado de Health Promotion Agency for Northern Ireland. Nutrition and dental health guidelines for professionals. Belfast: National Library of Guidelines; 2008). 
mentar significativamente o risco de CPI, mas a administração pelo biberão de leite açucarado ou outras bebidas que contenham açúcares simples, incluindo sumos naturais, aumenta o risco de CPI. ${ }^{1}$

- A chupeta não deve ser adocicada com açúcares ou bebidas açucaradas. ${ }^{1,13}$

- Bebidas que contenham açúcares simples, incluindo sumos naturais, não devem ser dados entre refeições. Deve ser dada água ou leite.,13

- Os alimentos que contenham açúcares simples ou cuja confecção adicione açúcares simples devem ser restritos, sempre que possível, às refeições. . $^{1,6,713}$

- As bebidas e os doces confeccionados com adoçantes devem ser preferidos aos confeccionados com açúcares simples. Os polióis, como o xilitol e o sorbitol têm sido largamente estudados. A evidência actual é de que são não cariogénicos e são alternativas seguras à sacarose para a confecção de produtos de confeitaria e outros alimentos. ${ }^{1,6,13}$

- A fruta, os vegetais frescos e o iogurte natural são alternativas menos cariogénicas para os lanches. O queijo parece ser protector quanto ao risco de cáries - estimula a secreção salivar neutralizando outros ácidos da dieta e aumenta a concentração de cálcio na placa. ${ }^{1,13}$

- A amamentação deve ser promovida e deve ser em exclusividade até aos 6 meses. Não existe limite superior de idade para deixar de amamentar. ${ }^{1,11}$ Estudos que compararam as propriedades cariogénicas do leite materno, do leite de vaca e dos leites adaptados concluíram que o leite materno não é cariogénico a menos que outro hidrato de carbono seja adicionado; o leite de vaca parece ser cariostático (relação neutra ou negativa com o desenvolvimento de cárie dentária), contudo, não deve ser administrado antes do $1^{\circ}$ ano de idade. Os leites adaptados estão associados a um risco acrescido de cárie dentária e, destes, o leite de soja, é teoricamente mais cariogénico por conter glucose em vez de lactose. ${ }^{1}$

- Os medicamentos pediátricos contêm, frequentemente, sacarose e podem aumentar o risco de cárie dentária se administrados com frequência. ${ }^{1,3,13}$ Nestas situações, deve optar-se por uma fórmula não açucarada, se disponível; ou optar-se apresentação em comprimidos em vez de xaropes, se viável; ou optar-se pela administração às refeições, se não condicionar a biodisponibilidade do medicamento.

\section{Aumentar a resistência dos dentes}

O processo cariogénico é semelhante na dentição primária e secundária. Contudo, os dentes da dentição primária são constituídos por uma camada de dentina e de esmalte mais finas, e, ao contrário do que acontece com a dentição secundária, as superfícies proximais são mais frequentemente envolvidas no processo cariogénico do que as superfícies oclusais. ${ }^{1}$ Estas particularidades tornam a dentição primária mais susceptível ao processo cariogénico, e que este processo seja mais agressivo, de progressão mais rápida, com as lesões a atingirem rapidamente a polpa dentária.

A erosão dentária pode agravar esta maior fragilidade da dentição primária. A erosão dentária caracterizase, tal como a cárie, pela destruição do tecido duro dos dentes pela acção de ácidos mas que não são produzidos por bactérias. A etiologia é igualmente multifactorial. Uma importante fonte destes ácidos é a alimentação. ${ }^{13,14}$

\section{MEDIDAS PREVENTIVAS DE FRAGILIDADE DENTÁRIA}

- A prescrição de suplementos sistémicos de flúor à grávida não demonstrou ser benéfica para a dentição primária da criança pelo que não é recomendada. ${ }^{1,6,7}$

- Alguns estudos sugerem que os filhos de mães com défices de vitamina $\mathrm{D}$ ou cálcio durante a gravidez têm maior risco de desenvolver defeitos no esmalte dos dentes de ambas as dentições. São necessários mais estudos que avaliem a eficácia e possíveis efeitos laterais desta suplementação. ${ }^{15}$

\section{MEDIDAS PREVENTIVAS DE EROSÃo DENTÁRIA}

- Sumos de fruta, águas minerais frutadas, bebidas gaseificadas não devem ser oferecidos. ${ }^{13,14}$

- Os sumos de fruta natural devem ser diluídos (1 parte de sumo para 10 partes de água), não devem ser açucarados e não devem ser administrados por biberão. ${ }^{13}$

- A água mineral gaseificada tem potencial erosivo desprezível mas não deve ser oferecida às crianças pela sua composição química. ${ }^{13,14}$

- A água e o leite são as alternativas mais seguras. ${ }^{13}$ Estudos que compararam as propriedades acidogénicas do leite materno, do leite de vaca e dos leites adaptados concluíram que o leite materno e o leite de vaca não são acidogénicos a menos que outro hidrato de 
carbono seja adicionado. Os leites adaptados são potencialmente mais acidogénicos, particularmente o leite de soja pela ausência de caseína, substância com efeito tampão. Por este motivo, e pelo maior risco cariogénico já referido, o leite de soja deve ser usado apenas quando indicação médica. ${ }^{1}$

- A ingestão de alimentos ácidos deve ser reduzida em frequência e sempre que possível limitada às refeições. Pode ser benéfico terminar a refeição com a ingestão de leite ou um pequeno cubo de queijo, que acelera a neutralização do $\mathrm{pH}$ da cavidade oral. ${ }^{13,14}$

- A escovagem dos dentes deve ser deferida pelo menos 20 minutos, idealmente 60 minutos, após a ingestão de um alimento ácido pelo risco de potenciar o desgaste abrasivo. ${ }^{14}$

- Alguns medicamentos são também fontes exógenas de ácidos. A vitamina $\mathrm{C}$ e algumas preparações de ferro são exemplos de medicamentos acidogénicos de prescrição relativamente frequente neste grupo etário. $^{14}$

\section{Avaliação do risco de cárie}

Numa tentativa de avaliar e predizer o risco de cárie dentária, têm sido desenvolvidas e apresentadas algumas escalas mas nenhuma predomina. Todas incluem múltiplas variáveis com o objectivo de aumentar a fiabilidade da estratificação do risco e intervir de forma preventiva e adequada..$^{1-3,7,6,8}$

Para além da dieta cariogénica/ingestão frequente de açúcares simples ao longo do dia e ausência/cuidados deficitários de higiene oral/exposição inadequada de flúor, já referidos, é considerado factor de risco acrescido para cárie dentária e constante aos diferentes trabalhos, o nível socioeconómico..$^{1-3,7,6,8}$ Outros são referidos, mas de forma menos constante.

A incidência, a prevalência e a gravidade da cárie dentária é maior em crianças de famílias economicamente carenciadas. ${ }^{1,6,7}$ Alguns estudos têm demonstrado que os hábitos alimentares da criança estão estreitamente relacionados com a classe social da família e o nível de escolaridade da mãe. Mães provenientes de meios mais carenciados e com menor formação têm maiores probabilidades de não amamentar, de usar biberão mais tempo e adicionar-lhe açúcar, de introduzir alimentos sólidos antes da idade recomendada, e de serem mais permissivas ao consumo de doces. ${ }^{6,16}$

\section{Referenciação ao Médico Dentista}

A primeira visita ao dentista deve ocorrer pelo primeiro aniversário ou 6 meses após a erupção do primeiro dente. ${ }^{2,6}$ Esta primeira consulta tem como objectivos reforçar orientações sobre os medidas de higiene oral, avaliar o risco individual de cárie e, em função deste, programar as consultas seguintes. A ida ao dentista deve ter como finalidade tratamentos preventivos e não curativos.

As recomendações apresentadas pelos diferentes artigos resultam de estudos de investigação que são maioritariamente realizados em crianças mais crescidas e já na dentição permanente e que são extrapolados para a dentição primária. Não foram encontrados estudos originais ou revisões de estudos que incidam exclusivamente neste grupo etário específico e um trabalho aborda especificamente a dificuldade de realizar estudos de saúde oral com crianças em idade pré-escolar. ${ }^{17}$

A promoção dos cuidados de saúde oral neste grupo etário, particularmente durante os primeiros 3 anos, é direccionada aos pais/cuidadores, sendo a adesão destes determinante para a sua implementação., ${ }^{1,12,18}$

Não existe, até à data, uma escala globalmente aceite que permita predizer o risco de cárie dentária de uma criança. Existem, contudo, pelo menos quatro factores de risco que são constantes às diferentes escalas encontradas: a existência de lesões activas de cáries, a dieta cariogénica, a ausência de cuidados de higiene oral e o baixo nível socioeconómico. ${ }^{1-3,7,6,8}$

O exame da cavidade oral exige conhecimentos específicos pelo que o Médico de Família deve receber formação que lhe permita identificar precocemente as lesões de cárie. ${ }^{1,3,19}$

As recomendações clínicas desta revisão baseada na evidência e respectivos graus de força segundo taxonomia SORT encontram-se resumidos no Quadro II.

\section{Em Portugal}

As medidas defendidas para as crianças do nascimento aos 6 anos de idade e para a grávida, apresentadas no Programa Nacional de Promoção da Saúde Oral (PNPSO), são concordantes com as recomendações clínicas desta revisão.

O Consenso sobre a utilização de fluoretos no âmbito do PNPSO defende igualmente as aplicações tópicas sob a forma de dentífricos fluoretados com um teor de 
QUADRO II. Evidência SORT - Recomendações clínicas

\section{Recomendações clínicas}

A avaliação do estado de saúde oral e o reforço das medidas preventivas realizadas regularmente nas consultas de Saúde Infantil são uma estratégia importante para a prevenção da CPI As crianças em idade pré-escolar devem escovar os dentes com um dentífrico fluoretado. A concentração de flúor do dentífrico deve ser 1.000 ppm $\mathrm{F} \pm 10 \%$

A escovagem deve iniciar-se aquando da erupção do $1^{\circ}$ dente, deve realizar-se duas vezes ao dia, e deve ser usada uma quantidade de dentífrico semelhante a «um borrão» ou «uma ervilha»

Os pais devem ser encorajados a reduzir comportamentos que promovem a transmissão/colonização precoce por S.mutans

A ingestão frequente de açúcares simples deve ser desaconselhada particularmente antes de dormir \begin{tabular}{|l|l} 
Evidência & Referências
\end{tabular}

1-3

$1-3,6,7,13$

$1-3,6$

$1,6,8,15$

$1,6-8,13$ fluoretos entre 1.000 e 1.500ppm administrados na escovagem diária logo desde a erupção do primeiro dente. A quantidade de dentífrico a utilizar até aos 6 anos deve ser idêntica ao tamanho da unha do $5^{\circ}$ dedo da mão da própria criança.

Não recomenda a suplementação sistémica com fluoretos à grávida, à criança com menos de 3 anos e em todas as situações em que o teor de flúor da água de consumo for superior a $0,3 \mathrm{ppm}$. A suplementação sistémica poderá ser feita após os 3 anos a crianças com alto risco de cárie dentária, sendo esta avaliação feita partir da conjugação dos seguintes factores de risco: evidência clínica de doença, análise dos hábitos alimentares, controlo da placa bacteriana, nível socioeconómico da família e história clínica da criança (Quadro III).

O PNPSO aborda também a importância da alimentação e da medicação crónica. Quanto à alimentação refere que deve ser fornecida informação aos pais das crianças com menos de 3 anos sobre os factores de cariogenicidade, desaconselhando o uso prolongado do biberão a partir do $1^{\circ}$ ano e alertando para a situação do bebé adormecer com o biberão na boca. Contra-indica a utilização de chupetas com açúcar ou mel e o consumo de guloseimas e refrigerantes, sobretudo fora das refeições. Quanto à medicação crónica, faz referência que nesta situação deve dar-se preferência à prescrição de medicamentos sem açúcar.

\section{CONCLUSÕES}

O processo cariogénico é um processo complexo, com determinantes biológicas, comportamentais e sociais.

$\mathrm{O}$ acesso limitado às consultas de estomatologia $\mathrm{e}$ medicina dentária, reforça a necessidade de ser o Médico de Família/Pediatra a actuar activamente na prevenção da CPI. A estes profissionais compete (1) a divulgação sistemática e continuada de medidas de educação alimentar com o objectivo de reduzir a exposição a factores de cariogenicidade; (2) a promoção de medidas de higiene oral, sendo fundamental conhecer o teor de fluoretos da água de consumo da comunidade com que trabalha; (3) a adequação terapêutica nas situações de medicação crónica quando possível e (4) a orientação para tratamento diferenciado, tão precoce quanto possível, das lesões que a prevenção não conseguir evitar.

A avaliação do risco individual de cárie deve ser realizado de forma sistemática nas consultas de vigilância de Saúde Materna e de Saúde Infantil e este arsenal de medidas educativas deve ser reforçado periodicamente.

Quanto ao PNPSO, as medidas que apresenta para a prevenção da CPI são concordantes com as recomendações clínicas encontradas nesta revisão e os critérios usados para avaliação do risco individual também incluem os quatro factores de risco constantes às diferentes escalas encontradas (Quadro III), revelando-se, por isso, um documento actualizado e útil. E se, numa primeira abordagem, nos parece muito orientado para a saúde escolar, o PNPSO aborda a necessidade das medidas nele apresentadas serem incluídas nos programas de saúde materna e de saúde infantil e juvenil porque é a única forma de prevenir a CPI. 
QUADRO III. Avaliação dos factores de risco para cárie dentária

(Adaptado de Programa Nacional de Promoção da Saúde Oral. Circular Normativa n. ${ }^{\circ}$ 1/DSE, de 18/01/05)

\begin{tabular}{l|l|l} 
Factores de Risco & Baixo Risco & Alto Risco \\
\hline Evidência clínica de doença & $\begin{array}{l}\text { Sem lesões de cárie } \\
\text { Nenhum dente perdido devido a cárie } \\
\text { Poucas ou nenhumas obturações }\end{array}$ & $\begin{array}{l}\text { Lesões activas de cárie } \\
\text { Extracções devido a cárie } \\
\text { Duas ou mais obturações } \\
\text { Aparelho fixo de ortodontia }\end{array}$ \\
\hline Análise dos hábitos alimentares & $\begin{array}{l}\text { Ingestão pouco frequente de } \\
\text { alimentos açucarados }\end{array}$ & $\begin{array}{l}\text { Ingestão frequente de alimentos } \\
\text { açucarados, em particular entre as refeições }\end{array}$ \\
\hline Utilização de Fluoretos & Uso regular de dentífrico fluoretado & $\begin{array}{l}\text { Não utilização regular de qualquer } \\
\text { dentífrico fluoretado }\end{array}$ \\
\hline Controlo da placa bacteriana & $\begin{array}{l}\text { Escovagem dos dentes duas ou } \\
\text { mais vezes por dia }\end{array}$ & $\begin{array}{l}\text { Não escova os dentes ou faz } \\
\text { uma escovagem pouco eficaz }\end{array}$ \\
\hline Nível socioeconómico da família & Médio ou alto & Baixo \\
\hline História clínica da criança & $\begin{array}{l}\text { Sem problemas de saúde } \\
\text { Ausência de medicação crónica }\end{array}$ & $\begin{array}{l}\text { Portador de deficiência física ou mental } \\
\text { Ingestão prolongada de medicamentos } \\
\text { cariogénicos } \\
\text { Doenças crónicas } \\
\text { Xerostomia }\end{array}$ \\
& &
\end{tabular}

\section{REFERÊNCIAS BIBLIOGRÁFICAS}

1. Scottish Intercollegiate Guidelines Network. Prevention and management of dental decay in the pre-school child. A national clinical guideline. Edinburgh: Scottish Intercollegiate Guidelines Network (SIGN); 2005. Disponível em: http://www.sign.ac.uk/pdf/sign83.pdf [acedido a 03/09/2009].

2. American Academy of Pediatric Dentistry. Guideline on periodicity of examination, preventive dental services, anticipatory guidance/counselling, and oral treatment for infants, children, and adolescents. Pediatr Dent 2008-2009; 30 (7 Suppl) 112-8.

3. Department of Health: Dental and Ophthalmic Services Division. Choosing better oral health: an oral health plan for England. London: Department of Health; 2005. Disponível em: http://www.parliament.uk/deposits/depositedpapers/2008/DEP2008-2661.pdf [acedido a 03/09/2009].

4. Eurotrials, Consultores Científicos. Programa Mês da Saúde Oral da Colgate e SPEMD, Portugal, Outubro, 2007. Relatório Estatístico. Draft No.3. 2008 Jul. Disponível em: http://www.spemd.pt/docs/soral_docs/RELAT_ESTAT2007.doc [acedido a 03/09/2009].

5. Programa Nacional de Promoção da Saúde Oral. Circular Normativa n. ${ }^{\circ}$ 1/DSE de 18/01/05. Disponível em: http://www.dgs.pt/upload/membro.id/ficheiros/i006694.pdf [acedido a 03/09/2009].

6. HealthPartners Dental Group and Clinics Caries Guideline. Minneapolis (MN): HealthPartners Dental Group; 2008. Disponível em: http://www.guideline.gov/summary/summary.aspx?doc_id= $12538 \& n b r=6455 \& s s=6 \& x l=999$ [acedido a 03/09/2009].

7. Campus G, Condò SG, Di Renzo G, Ferro R, Gattto R, Giuca MR, et al. National Italian Guidelines for caries prevention in 0 to 12 years-old children. Eur J Paediatr Dent 2007 Sep; 8 (3): 153-9.
8. National Institute for Health and Clinical Excellence. Guidance for midwives, health visitors, pharmacists and other primary care services to improve the nutrition of pregnant and breastfeeding mothers and children in low income households. London: National Institute for Health and Clinical Excellence - Public Health; 2008. Disponível em: http://www.nice.org.uk/PH011 [acedido a 03/09/2009].

9. Guide to Clinical Preventive Services, 2006: Recommendations of the U.S. Preventive Services Task Force. AHRQ Publication No. 06-0588. Rockville, MD: Agency for Healthcare Research and Quality; 2006. Disponível em http://www.ahrq.gov/clinic/pocketgd06/ [acedido a 03/09/2009].

10. American Academy of Family Physicians (AAFP). Summary of recommendations for clinical preventive services. Revision 6.4. Leawood (KS): American Academy of Family Physicians; 2007. Disponível em: http://www.guideline.gov/summary/summary.aspx?doc_id=11830 [acedido a 03/09/2009].

11. Gartner LM, Morton J, Lawrence RA, Naylor AJ, O'Hare D, Schanler RJ, et al. Breastfeeding and the use of human milk. Pediatrics 2005 Feb; 115 (2): 496-506.

12. Galganny-Almeida A, Queiroz MC, Leite AJ. The effectiveness of a novel infant tooth wipe in high caries-risk babies 8 to 15 months old. Pediatr Dent 2007 Jul-Aug; 29 (4): 337-42.

13. Health Promotion Agency for Northern Ireland. Nutrition and dental health - guidelines for professionals. Belfast: National Library of Guidelines; 2008. Disponível em: http://www.healthpromotionagency.org.uk/Resources/nutrition/pdfs/Nutrition_and_Dental_Health.pdf [acedido a 03/09/2009].

14. O'Sullivan E, Milosevic A. Diagnosis prevention and management of dental erosion. London: Royal College of Surgeons of England; 2007. 
Disponível em: http://www.rcseng.ac.uk/fds/clinical_guidelines/documents/erosion_guideline.pdf [acedido a 03/09/2009].

15. Feldens CA, Vítolo MR, Drachler M de L. A randomized trial of the effectiveness of home visits in preventing early childhood caries. Community Dent Oral Epidemiol 2007 Jun; 35 (3): 215-23.

16. Canadian Paediatric Society. Vitamin D supplementation: recommendations for Canadian mothers and infants. Paediatr Child Health 2007 Sep;12 (7): 583-98.

17. Chadwick BL, Treasure ET. Primary care research: difficulties recruiting preschool children to clinical trials. Int J Paediatr Dent 2005 May; 15 (3): 197-204.

18. Twetman S. Prevention of early childhood caries (ECC) - review of literature published 1998-2007. Eur Arch Paediatr Dent 2008 Mar; 9 (1): 12-8.

19. Slade GD, Rozier RG, Zeldin LP, Margolis PA. Training pediatric health care providers in prevention of dental decay: results from a randomized controlled trial. BMC Health Serv Res 2007 Nov 2; 7: 176.

\section{ENDEREÇO PARA CORRESPONDÊNCIA}

Darcília Maria de Oliveira Eusébio

Praceta Joaquim Silva Santos Rocha, $158,1^{\circ}$ Direito

4460-341 Senhora da Hora

Tlm: 964743302

E-mail: eusebiodarcilia@gmail.com

Recebido em 22/12/2008

Aceite para publicação em 03/07/2009

Os autores declararam não possuir conflitos de interesses

\section{ABSTRACT}

\section{INFANT ORAL HEALTH - A CHALLENGE FOR PRIMARY CARE PHYSICIANS}

Objectives: Review the main recommendations evidence based to prevent ECC in primary health care.

Data Sources: PubMed, National Library of Guidelines, National Guideline Clearinghouse, The Cochrane Library, CMA, DARE, TRIP Database, Bandolier.

Review Methods: Articles were searched using the following key words (MeSH terms): Dental caries, Infant, Primary Health Care. The search was limited to guidelines, meta-analysis; systematic reviews and randomized controlled trials, articles written in English and Portuguese, with abstract available published between January 2005 and November 2008. To evaluate the level of evidence, the rating system of the American Family Physician (Strength Of Recommendation Taxonomy-SORT) was used.

Results: Of 54 considered articles, there were selected 17 of which 12 Guidelines, a systematic review and 4 randomized controlled trials. The effective strategies for preventing ECC are general anticipatory guidance to prevent early colonization, cleansing the infant's teeth as soon as they erupt, providing education on the cariogenicity of certain foods and beverages, evaluating and optimizing fluoride exposure and early establishment of a dental home (early diagnosis/at risk).

Conclusions: The Family Physician/Paediatrician is frequently the first and the only professional of health to observe and accompanying the development of the children. He has therefore an important paper in the prevention of the ECC by providing general anticipatory guidance, oral health risk assessment and early establishment of a dental home.

Keywords: Dental Caries; Infant; Primary Health Care. 